\title{
Preliminary evaluation of ${ }^{18}$ F-AIF-NOTA-MAL-Cys ${ }^{40}$-Exendin-4 in rodent heart after myocardial ischemia and reperfusion
}

\author{
XIETIAN PAN $^{1}$, QING XU $^{2}$, JIANGWEI CHEN $^{3}$, TINGTING WANG $^{1}$, \\ MINGMING ZHANG ${ }^{1}$, HAICHANG WANG ${ }^{1}$ and HAOKAO GAO ${ }^{3}$ \\ ${ }^{1}$ Department of Cardiology, Tangdu Hospital, The Fourth Military Medical University, Xi'an, Shaanxi 710038; \\ ${ }^{2}$ Department of Radiation Oncology, The Affiliated Bayi Hospital of Nanjing University of Chinese Medicine, Nanjing, \\ Jiangsu 210002; ${ }^{3}$ Department of Cardiology, Xijing Hospital, The Fourth Military Medical University, \\ Xi'an, Shaanxi 710032, P.R. China
}

Received April 20,2018; Accepted May 15, 2019

DOI: $10.3892 / \mathrm{mmr} .2019 .10432$

\begin{abstract}
Glucagon-like peptide-1 (GLP-1) and its receptor (GLP-1R) exert cardioprotective effects after myocardial ischemia and reperfusion (MI/R) in animal models and human clinical trials. Receptor imaging with positron emission tomography (PET) provides a non-invasive method for monitoring GLP-1R expression. In the present study, a fluorine-18-labeled aluminum fluoride exendin- 4 analog $\left[{ }^{18} \mathrm{~F}\right.$-AlF conjugated with 1,4,7-triazacyclononanetriacetic acid (NOTA)-maleimide (MAL)-Cys ${ }^{40}$-exendin-4] was synthesized and evaluated in a rat MI/R model for GLP-1R imaging. NOTA-MAL-Cys ${ }^{40}$-exendin- 4 was synthesized by coupling $\mathrm{Cys}^{40}$-exendin- 4 with NOTA-MAL. NOTA-MAL-Cys ${ }^{40}$-exendin- 4 was then conjugated with ${ }^{18} \mathrm{~F}-\mathrm{AlF}$ to obtain ${ }^{18} \mathrm{~F}$-AlF-NOTA-MAL-Cys ${ }^{40}$-exendin- 4 . The yield of ${ }^{18} \mathrm{~F}$-AlF-NOTA-MAL-Cys ${ }^{40}$-exendin- 4 was $18.5 \pm 3.4 \%$ (not decay corrected). The process was completed within $\sim 30 \mathrm{~min}$. In rat MI/R models, the tracer exhibited specific binding to GLP-1R and an appropriate signal-to-noise ratio. At $8 \mathrm{~h}$ post-MI/R, tracer uptake reached its peak $[0.35 \pm 0.053 \%$ of injected dose (\%ID)/g; $\mathrm{n}=6]$ in ischemic myocardium. Localized tracer uptake decreased 1 day $(0.20 \pm 0.032 \% \mathrm{ID} / \mathrm{g}$; $\mathrm{n}=6)$ and 3 days $(0.16 \pm 0.017 \% \mathrm{ID} / \mathrm{g} ; \mathrm{n}=6)$ post-MI/R compared with $8 \mathrm{~h}$ post-MI/R, but still remained higher compared with sham-operated groups $(0.06 \pm 0.012 \% \mathrm{ID} / \mathrm{g} ; \mathrm{n}=6)$. Pre-injected
\end{abstract}

Correspondence to: Dr Haokao Gao, Department of Cardiology, Xijing Hospital, The Fourth Military Medical University, 169 Changlexi Road, Xi'an, Shaanxi 710032, P.R. China

E-mail: hk_gao@163.com

Professor Haichang Wang, Department of Cardiology, Tangdu Hospital, The Fourth Military Medical University, 1 Xinsi Road, Xi'an, Shaanxi 710038, P.R. China

E-mail:wanghc@fmmu.edu.cn

Key words: glucagon-like peptide-1 receptor, exendin-4, positron emission tomography imaging, myocardial reperfusion injury, fluorine-18 unlabeled exendin-4 effectively blocked tracer accumulation $(0.09 \pm 0.041 \% \mathrm{ID} / \mathrm{g} ; \mathrm{n}=6)$. In conclusion, ${ }^{18} \mathrm{~F}-\mathrm{AlF}-\mathrm{NOTA}-\mathrm{MA}$ L-Cys ${ }^{40}$-exendin- 4 demonstrated favorable characteristics for GLP-1R imaging following MI/R. PET imaging using ${ }^{18} \mathrm{~F}-\mathrm{Al}$ F-NOTA-MAL-Cys ${ }^{40}$-exendin-4 in rodent hearts after MI/R revealed a dynamic pattern of GLP-1R upregulation.

\section{Introduction}

Although mortality rates of coronary heart disease worldwide have declined over the past four decades, the disease remains responsible for approximately one-third of all deaths of individuals over the age of 35 (1). Upon acute myocardial ischemia (MI) due to coronary occlusion, restoring myocardial perfusion through either percutaneous coronary intervention or thrombolytic therapy is the most effective treatment. However, reperfusion causes ischemia/reperfusion (I/R) injury, which aggravates myocardial damage $(2,3)$. Recent research suggests great interest in alleviating reperfusion injury following myocardial ischemia $(4,5)$.

Glucagon-like peptide-1 (GLP-1) is a 30-amino-acid-long gut hormone secreted from intestinal endocrine L-cells $(6,7)$. GLP-1 exerts physiological functions through binding to its receptor (GLP-1R), which is a class B heterotrimeric G-protein-coupled receptor (8). GLP-1R is expressed in a number of tissues, including pancreatic islets, heart, lung, kidney, stomach, intestine, pituitary, skin and nervous tissue. Previous studies have demonstrated that GLP-1 exerts cytoprotective effects in the heart after I/R injury (9-11). Thus, in addition to treating hyperglycemia, GLP-1 offers promising prospects in treating reperfusion injury of the myocardium. However, the cardioprotective effects of GLP-1 after MI/R injury are temporary (9). Therefore, in vivo imaging of GLP-1R may be a useful tool to further study the role of GLP-1 and GLP-1R in treating reperfusion injury.

GLP-1 cannot be used as an imaging tracer as it is rapidly degraded by dipeptidyl-peptidase-IV (DPP-IV) upon being released into the blood (12). Exendin-4, an analog of GLP-1, has a 53\% amino acid homology with GLP-1, but is resistant to DPP-IV, thus prolonging its half-life $\left(\mathrm{T}_{1 / 2}\right)$ in plasma (13). Numerous attempts have been made to attach exendin- 4 to 
radioisotopes, such as ${ }^{111} \mathrm{In},{ }^{99 \mathrm{~m}} \mathrm{Tc}$ for single-photon emission computed tomography (SPECT) and ${ }^{68} \mathrm{Ga},{ }^{64} \mathrm{Cu}$ for positron emission tomography (PET) (14-16). However, these combinations have certain limits; SPECT has a lower density resolution compared with PET, and ${ }^{68} \mathrm{Ga}$ and ${ }^{64} \mathrm{Cu}$ are not commonly used in the clinic. Fluorine-18 $\left({ }^{18} \mathrm{~F}\right)$, however, has suitable imaging properties $\left(\beta^{+}, 0.635 \mathrm{MeV} 97 \% ; \mathrm{T}_{1 / 2}, 110 \mathrm{~min}\right)$. Previously, ${ }^{18} \mathrm{~F}$-4-fluorobenzamido-N-ethylamino-maleimide (FBEM)-Cys ${ }^{40}$-exendin-4 was developed for GLP-1R imaging by PET; ${ }^{18}$ F-FBEM-Cys ${ }^{40}$-exendin-4 exhibited high affinity with GLP-1R in an INS-1 rat insulinoma xenograft model and a rat $\mathrm{MI} / \mathrm{R}$ model $(17,18)$. However, the radiosynthesis of ${ }^{18} \mathrm{~F}$-FBEM-Cys ${ }^{40}$-exendin-4 is time-consuming, which complicates the application of the tracer.

In the present study, a radiotracer of GLP-1R was synthesized by conjugating ${ }^{18} \mathrm{~F}$-labled aluminum fluoride $\left({ }^{18} \mathrm{~F}-\mathrm{AlF}\right)$ with 1,4,7-triazacyclononanetriacetic acid (NOTA)-maleimide (MAL)-Cys ${ }^{40}$-exendin-4 in a one-step procedure. Subsequently, ${ }^{18}$ F-AlF-NOTA-MAL-Cys ${ }^{40}$-Exendin- 4 was evaluated in a rat $\mathrm{MI} / \mathrm{R}$ model for longitudinal PET imaging.

\section{Materials and methods}

Materials and high-performance liquid chromatography (HPLC). $\mathrm{Cys}^{40}{ }^{40 x e n d i n}-4$ was a generous gift from Professor Min Yang (Jiangsu Institute of Nuclear Medicine, Nanjing, China). NOTA-MAL was purchased from CheMatech. ${ }^{18}$ F-labled fluoride was obtained using the HM-67 cyclotron (Sumitomo Heavy Industries, Ltd.) at the Jiangsu Institute of Nuclear Medicine by proton irradiation of ${ }^{18} \mathrm{O}$-enriched water. All other commercially obtained reagents were of analytical grade. For semi-preparative HPLC, an Xbridge C18 HPLC column (5 $\mu \mathrm{m}, 250 \times 9 \mathrm{~mm}$; Waters Corporation) and a Waters HPLC system with a Q1 Waters 2998 photodiode array detector (Waters Corporation) were used. The system was maintained at room temperature and the sample quantity was $1 \mathrm{ml}$. No internal standards were used. The flow rate was $5 \mathrm{ml} / \mathrm{min}$. The linear gradient started at $95 \%$ A $[0.1 \%$ trifluoroacetic acid (TFA) in water] and 5\% B (0.1\% TFA in acetonitrile) for $2 \mathrm{~min}$, and increased to $35 \% \mathrm{~A}$ and $65 \% \mathrm{~B}$ at $32 \mathrm{~min}$.

Preparation of NOTA-MAL-Cys ${ }^{40}$-exendin-4 analogs. The sequence ofCys ${ }^{40}$-exendin-4isHis-Gly-Glu-Gly-Thr-Phe-Thr-S er-Asp-Leu-Ser-Lys-Gln-Met-Glu-Glu-Glu-Ala-Val-Arg-LeuPhe-Ile-Glu-Trp-Leu-Lys-Asn-Gly-Gly-Pro-Ser-Ser-Gly-Ala-ProPro-Pro-Ser-Cys- $\mathrm{NH}_{2}$. Cys ${ }^{40}$-exendin-4 was conjugated with NOTA-MAL as previously described (19). Briefly, NOTA-MAL $(2.16 \mathrm{mg}, 3.2 \mu \mathrm{mol})$ was mixed with $\mathrm{Cys}^{40}$-exendin-4 $(6.77 \mathrm{mg}, 1.57 \mu \mathrm{mol})$ and dissolved in $6 \mathrm{ml}$ $0.4 \mathrm{M}$ ammonium acetate. Subsequently, $400 \mu \mathrm{l}$ acetonitrile was added. Following stirring at $40^{\circ} \mathrm{C}$ overnight, the mixture was purified by semi-preparative HPLC, aforementioned. The desired product was collected and lyophilized.

Radiosynthesis of ${ }^{18} \mathrm{~F}$-AlF-NOTA-MAL-Cys ${ }^{40}$-exendin-4. In a $2 \mathrm{ml}$ centrifuge tube, $70 \mu \mathrm{g}$ NOTA-MAL-Cys ${ }^{40}$-exendin- 4 and $10 \mu \mathrm{l}$ double-distilled water $\left(\mathrm{ddH}_{2} \mathrm{O}\right)$ were charged, and $10 \mu \mathrm{l}$ glacial acetic acid $\left(\mathrm{CH}_{3} \mathrm{COOH}\right)$ was added. Cyclotron target water containing ${ }^{18} \mathrm{~F}(\sim 50 \mu \mathrm{l}$ containing $90 \mathrm{mCi})$ was added, followed by $280 \mu \mathrm{l}$ acetonitrile $\left(\mathrm{CH}_{3} \mathrm{CN}\right)$ and $3 \mu \mathrm{l}$ aluminum chloride $(2 \mathrm{mM})$ in $0.5 \mathrm{M} \mathrm{NaOAc}(\mathrm{pH}=4)$. After complete mixing, the resulting solution was incubated in oil at $100^{\circ} \mathrm{C}$ for $10 \mathrm{~min}$. Following cooling, the reaction mixture was diluted

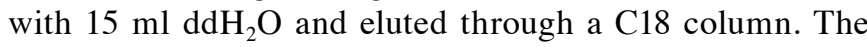
product was subsequently re-eluted with $20 \%$ aqueous ethanol containing $10 \mathrm{mM} \mathrm{HCl}$. The elute was treated with $100 \mu \mathrm{l}$ of $0.1 \mathrm{M} \mathrm{NaOAc}(\mathrm{pH} 4)$ and concentrated to $200 \mu \mathrm{l}$ total volume under a stream of argon. The sample was diluted with PBS for animal injections.

Quality control of ${ }^{18} \mathrm{~F}$-AlF-NOTA-MAL-Cys $\mathrm{s}^{40}$-exendin-4. A sample of the elute $(10 \mu \mathrm{l})$ was analyzed by reversed-phase HPLC on a C18 column (5 $\mu \mathrm{m}, 250 \times 4.6 \mathrm{~mm}$; Phenomenex) with linear gradient at $1 \mathrm{ml} / \mathrm{min}$, as previously described (19). UV absorption and radioactivity were monitored by a Waters 2487 dual $\lambda$ absorbance detector (Waters corporation) and a Radiomatic 610TR flow scintillation analyzer (PerkinElmer, Inc.), respectively. Mass spectra were obtained using a Q1 Waters LC-MS system (Waters corporation) featuring an Acquity UPLC system coupled with a Waters Q-Tof Premier high-resolution mass spectrometer (Waters Corporation). Positive mode was used with a vaporizer temperature of $300^{\circ} \mathrm{C}$, a nebulizer pressure of $20 \mathrm{psi}$ and a gas flow rate of $5 \mathrm{l} / \mathrm{min}$. Positive ions were acquired in the multiple reaction monitoring mode (collision energy, $10 \mathrm{eV}$ ).

Animal model of myocardial ischemia and reperfusion. All animal studies were conducted in accordance with the principles and procedures outlined in the Guide for the Care and Use of Laboratory Animals, and the protocols were approved by the Laboratory Animal Ethics Committee of The Fourth Military Medical University (Xi'an, China). A total of 36 adult male Sprague-Dawley rats (6-8 weeks old, 200-250 g) obtained from Laboratory Animal Center of the Fourth Military Medical University were used. The animals were housed under a $12: 12$-h light/dark cycle at $25^{\circ} \mathrm{C}$ and $50 \%$ relative humidity, with access to food and water ad libitum. Intraperitoneal injection of $3 \%$ pentobarbital sodium was conducted for anesthesia at a dose of $50 \mathrm{mg} / \mathrm{kg}$ initially with modifications according to the depth of anesthesia (20), and the animals were intubated for mechanical ventilation. MI/R models were established by ligation of the left anterior descending coronary artery 2-3 $\mathrm{mm}$ from the tip of the auricle with a 6-0 polypropylene suture. Reperfusion was achieved thirty minutes after the coronary artery occlusion by removal of the suture. In the sham-operated group, a suture was placed in the myocardium without ligation of the left coronary artery. The occlusion and reperfusion were confirmed by ST-segment elevation on an electrocardioscope and by ${ }^{18} \mathrm{~F}$-fluorodeoxyglucose (FDG) imaging at post-surgery day 1 (see the 'Micro-PET imaging' section below for details).

Echocardiographic assessment of left ventricular (LV) contractility. Echocardiography was performed at day 1 post-MI/R. Gaseous anesthesia was conducted using $3 \%$ isoflurane, and the rats were placed on the scanning table. Echocardiographic images were obtained using a small-animal high-resolution imaging unit and a $30-\mathrm{MHz}$ linear transducer (Vevo 770; FUJIFILM VisualSonics, Inc.). LV end-diastolic diameter (LVEDD) and LV end-systolic 
diameter (LVESD) were measured using a parasternal short-axis view, and LV fractional shortening was calculated as [(LVEDD-LVESD)/LVEDD] x100\%. All measurements were averaged over three successive cardiac cycles.

Micro-PET imaging. PET scans and image analysis were performed using an Inveon micro-PET (Siemens Medical Solutions USA, Inc.). At 8 h, 1 day, 3 days, and 1 week post-MI/R, each rat was injected in the tail vein with $18.5 \mathrm{MBq}$ $(500 \mu \mathrm{Ci}){ }^{18} \mathrm{~F}$-AlF-NOTA-MAL-Cys ${ }^{40}$-exendin-4 under $3 \%$ isoflurane anesthesia ( $\mathrm{n}=6$ rats/group). Ten-minute static PET scans were acquired $1 \mathrm{~h}$ post-injection. For the blocking experiment, $8 \mathrm{mg} / \mathrm{kg}$ of unlabeled $\mathrm{Cys}^{40}$-exendin- 4 was pre-injected $10 \mathrm{~min}$ prior to the injection of labeled $\mathrm{Cys}^{40}$-exendin-4 at post-MI/R day $1(n=6)$. The images were reconstructed using a three-dimensional ordered subsets expectation maximum algorithm, and no correction was applied for attenuation or scatter. For each scan, regions of interest (ROIs) were drawn around the ischemic myocardium, lung and surgical wounds using the vendor software ASI Pro 6.7.1.1 (Siemens AG) on whole-body coronal images. The radioactivity concentration (accumulation) within myocardium was obtained from mean pixel values within the multiple ROI volume, which was converted to $\mathrm{MBq} / \mathrm{ml} / \mathrm{min}$ using a conversion factor. The conversion to $\mathrm{MBq} / \mathrm{g} / \mathrm{min}$ assumed tissue density of $1 \mathrm{~g} / \mathrm{ml}$. The values were divided by the administered activity to obtain an image ROI-derived percentage of injected dose per gram $(\% \mathrm{ID} / \mathrm{g})$. Following ${ }^{18} \mathrm{~F}-\mathrm{AlF}-\mathrm{NOTA}-\mathrm{MAL}-\mathrm{Cys}^{40}$-exendin-4 scanning, rats were kept on the scanning gantry for image co-registration for $1 \mathrm{~h}$ and injected with $18.5 \mathrm{MBq}(500 \mu \mathrm{Ci})$ of ${ }^{18} \mathrm{~F}$-FDG. After $1 \mathrm{~h}, 10$-min static scans were performed, and images were reconstructed and analyzed using the same procedure.

GLP-1R immunohistochemical staining. Heart samples from the rats were harvested after the rats were fully anesthetized and immediately placed into $10 \%$ formalin for fixation at room temperature for $24 \mathrm{~h}$. Formalin-fixed samples were embedded in paraffin. Tissue sections $(5-\mu \mathrm{m})$ were dried for $1 \mathrm{~h}$ at $90^{\circ} \mathrm{C}$ prior to deparaffinization in xylene, rehydrated by a series of descending ethanol concentrations and subsequently washed with PBS. Antigen retrieval was achieved by heat treatment at $95^{\circ} \mathrm{C}$ in a pressure cooker for $2 \mathrm{~min}$ in $10 \mathrm{mM}$ citrate buffer ( $\mathrm{pH}$ 6.5). Endogenous peroxidase was blocked at room temperature using $3 \%$ hydrogen peroxide for $20 \mathrm{~min}$. The tissue section was incubated at $4^{\circ} \mathrm{C}$ overnight with a rabbit anti-rat polyclonal GLP-1R antibody (1:200; cat. no. ab188602; Abcam). After washing with PBS, the slide was incubated with a horseradish peroxidase (HRP)-labeled goat anti-rabbit IgG antibody (1:50; cat. no. ab6721; Abcam) for $30 \mathrm{~min}$ at room temperature. Diaminobenzidine (Sangon Biotech Co., Ltd.) was used for staining according to the manufacturer's protocols, and the analysis was performed using an Olympus BX41 optical microscope (magnification, x20; Olympus Corporation).

Western blot analysis of GLP-1R. The area of ischemia was defined as the region appearing pale. The corresponding areas of the heart were divided into different samples. The samples of each group $(n=3)$ were homogenized, suspended in RIPA buffer (Sigma-Aldrich, Merck KGaA) and protease inhibitor cocktail (Roche Applied Science), and centrifuged at $14,000 \mathrm{x} \mathrm{g}$ for $10 \mathrm{~min}$ at $4^{\circ} \mathrm{C}$. Protein concentration of the supernatant was measured by the bicinchoninic acid method; $50 \mu \mathrm{g}$ of protein was separated by Tris-glycine $10 \%$ SDS-PAGE and transferred to a nitrocellulose membrane. Blocking was performed with 5\% skimmed milk and $0.1 \%$ bovine serum albumin (Gibco; Thermo Fisher Scientific, Inc.) at room temperature for $1 \mathrm{~h}$. The membrane was incubated with rabbit anti-rat polyclonal GLP-1R primary antibody (1:500; cat. no. ab188602; Abcam) at $4^{\circ} \mathrm{C}$ overnight, washed with PBS, and incubated with HRP-labeled goat anti-rabbit IgG antibody (1:300; cat. no. ab6721; Abcam) at room temperature for $1 \mathrm{~h}$. Chemiluminescence was performed with chemiluminescent HRP substrate using a SuperSignal West Pico Chemiluminescence Kit Detection System (Pierce, Thermo Fisher Scientific, Inc.). $\beta$-actin (1:500; cat. no. ab8227; Abcam) was used as internal control; each protein band was quantified using ImageJ software (v1.8.0, National Institutes of Health) and normalized to $\beta$-actin.

Statistical analysis. Data are expressed as mean \pm SD. Statistical analysis was performed by one-way analysis of variance and a Student-Newman-Keuls multiple comparison post hoc test was performed to identify differences between groups. $\mathrm{P}<0.05$ was considered to indicate a statistically significant difference.

\section{Results}

Chemistry and radiochemistry. NOTA-MAL-Cys ${ }^{40}$-exendin- 4 was synthesized by NOTA-MAL and $\mathrm{Cys}^{40}$-exendin- 4 . Following purification by semi-preparative HPLC, the yield of NOTA-MAL-Cys ${ }^{40}$-exendin- 4 was $68 \%$. Mass spectrometry results indicated a mass-to-charge ratio of $4,712.83$ for $\mathrm{MH}^{+}$ $\left(\mathrm{C}_{205} \mathrm{H}_{314} \mathrm{~N}_{56} \mathrm{O}_{68} \mathrm{~S}_{2}\right.$; calculated molecular weight, 4,713; Fig. 1). Radiosynthesis of ${ }^{18} \mathrm{~F}$-AlF-NOTA-MAL-Cys ${ }^{40}$-exendin-4 was completed in $30 \mathrm{~min}$, and the yield was $18.5 \pm 3.4 \%$ (no decay corrected) with a purity of $>95 \%$. The retention time of ${ }^{18} \mathrm{~F}$-AlF-NOTA-MAL-Cys ${ }^{40}$-exendin-4 obtained by analytical HPLC was 23 min (Fig. 2).

Electrocardioscope monitoring during establishment of the MI/R models was used to confirm I/R conditions by ST-T segment change (Fig. 3A). At MI/R day $1,{ }^{18}$ F-FDG PET scanning demonstrated a significant defect in the anterolateral wall of the LV (white arrow), whereas no uptake defect was observed in the sham-operated 1 day group ( $n=6$; Fig. 3B). On the same day, M-mode high-resolution ultrasound was performed and revealed a decrease in the amplitude of the anterolateral wall of LV (Fig. 3C). Fractional shortening was decreased from $69 \pm 5.2$ to $44 \pm 3.6 \%$ in rats following surgery; no compromised cardiac function was observed by M-mode high-resolution ultrasound in sham-operated animals (Fig. 3C).

Image colocalization. ${ }^{18} \mathrm{~F}-\mathrm{FDG}$ PET imaging was used to identify the area of ischemia. Co-registration of ${ }^{18} \mathrm{~F}-\mathrm{AlF}-\mathrm{NO}$ TA-MAL-Cys ${ }^{40}$-exendin-4 PET and ${ }^{18}$ F-FDG PET provided a visual method for anatomically localizing the high-radioactivity area of ${ }^{18} \mathrm{~F}$-AlF-NOTA-MAL-Cys ${ }^{40}$-exendin- 4 in hearts. 
His-Gly-Glu-Thr-Phe-Thr-Ser-Asp-Leu-Ser-Lys-Gln-Met-Glu-Glu-Glu-Ala-Val-Arg-Leu-Phe-Ile-GluTrp-Leu-Lys-Asn-Gly-Gly-Pro-Ser-Ser-Gly-Ala-Pro-Pro-Pro-Ser-Cys-NH<smiles>O=C(O)CN1CCCN(CC(=O)NCCN2C(=O)C=CC2=O)CCN1CC(=O)O</smiles>

Cys ${ }^{40}$-exendin- 4

His-Gly-Glu-Thr-Phe-Thr-Ser-Asp-Leu-Ser-Lys-Gln-Met-Glu-Glu-Glu-Ala-Val-Arg-Leu-Phe-Ile-GluTrp-Leu-L ys-Asn-Gly-Gly-Pro-Ser-Ser-Gly-Ala-Pro-Pro-Pro-Ser-NH

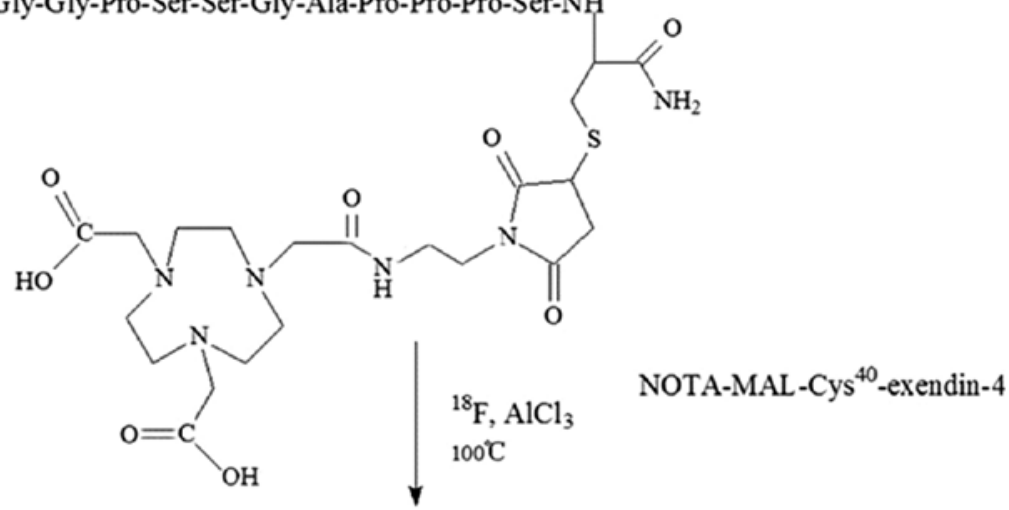

His-Gly-Glu-Thr-Phe-Thr-Ser-Asp-Leu-Ser-Lys-Gln-Met-Glu-Glu-Glu-Ala-Val-Arg-L eu-Phe-Ile-GluTrp-Leu-Lys-Asn-Gly-Gly-Pro-Ser-Ser-Gly-Ala-Pro-Pro-Pro-Ser-NH

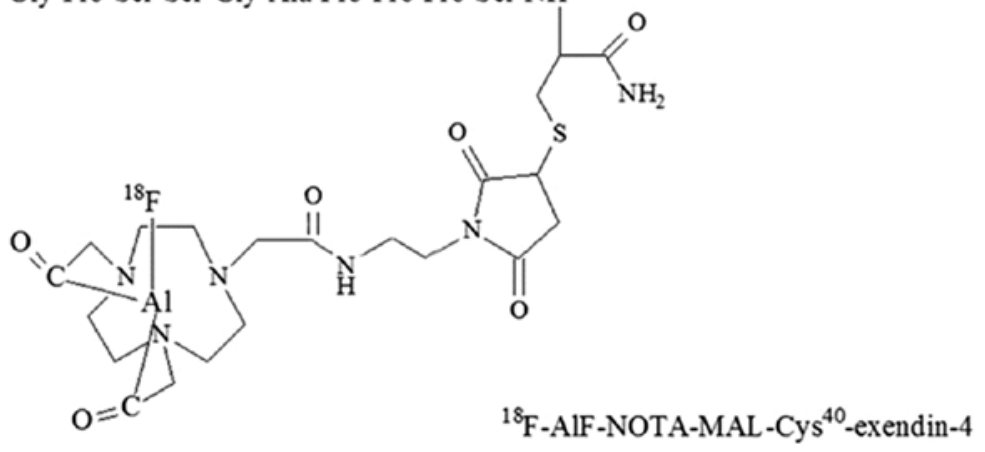

Figure 1. Scheme of radiosynthesis of ${ }^{18} \mathrm{~F}-\mathrm{AlF}-\mathrm{NOTA}-\mathrm{MAL}-\mathrm{Cys}^{40}$-exendin-4. NOTA-MAL-Cys ${ }^{40}$-exendin-4 was synthesized by coupling Cys ${ }^{40}$-exendin- 4 with NOTA-MAL. NOTA-MAL-Cys ${ }^{40}$-exendin-4 was then conjugated with ${ }^{18} \mathrm{~F}$-AlF to obtain ${ }^{18} \mathrm{~F}-\mathrm{AlF}-\mathrm{NOTA}-\mathrm{MAL}-\mathrm{Cys}{ }^{40}$-exendin-4. ${ }^{18} \mathrm{~F}$, fluorine-18; AlF, aluminum fluoride; Cys, cysteine; MAL, maleimide; NOTA, 1,4,7-triazacyclononanetriacetic acid.

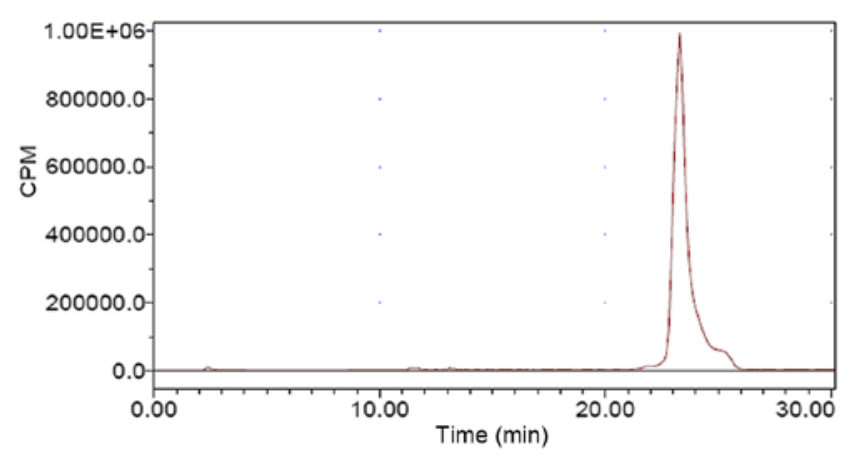

Figure 2. Radio HPLC chromatogram of ${ }^{18} \mathrm{~F}-\mathrm{AlF}-\mathrm{NOTA}-\mathrm{MAL}-\mathrm{Cys}{ }^{40}$-exe ndin-4. $\mathrm{T}$ he retention time of ${ }^{18} \mathrm{~F}-\mathrm{AlF}-\mathrm{NOTA}-\mathrm{MAL}-\mathrm{Cys}{ }^{40}$-exendin-4 was 23 min. ${ }^{18} \mathrm{~F}$, fluorine-18; AlF, aluminum fluoride; $\mathrm{CPM}$, count per minute; $\mathrm{Cys}$, cysteine; MAL, maleimide; NOTA, 1,4,7-triazacyclononanetriacetic acid.

To facilitate image co-registration, the rats were kept in the scanning gantry under anesthesia during tracer injection and imaging acquisition. Representative myocardial transaxial slices from one rat following in vivo $\mathrm{PET}$ imaging of ${ }^{18} \mathrm{~F}-\mathrm{AlF}$ -NOTA-MAL-Cys ${ }^{40}$-exendin- 4 and ${ }^{18} \mathrm{~F}$-FDG are presented in Fig. 4. Compared with sham-operated rats, the hearts of $\mathrm{MI} / \mathrm{R}$ day 1 rats exhibited decreased ${ }^{18} \mathrm{~F}-\mathrm{FDG}$ uptake and increased ${ }^{18} \mathrm{~F}$-AlF-NOTA-MAL-Cys ${ }^{40}$-exendin-4 uptake in the anterolateral wall of the LV. The area of ischemic myocardium was matched between ${ }^{18} \mathrm{~F}$-FDG and ${ }^{18} \mathrm{~F}$-AlF-NOTA-MAL-Cys ${ }^{40}$-e xendin-4 uptake (Fig. 4).

Dynamic change in GLP-1R in PET imaging. Representative transaxial micro-PET images of ${ }^{18} \mathrm{~F}$-AlF-NOTA-MAL-Cys ${ }^{40}$ exendin-4 at different time points following $\mathrm{MI} / \mathrm{R}$ are presented in Fig. 5A. In the lung, the area of ischemia and surgery wound exhibited higher uptake of ${ }^{18} \mathrm{~F}$-AlF-NOTAMAL-Cys ${ }^{40}$-exendin-4 compared with surrounding tissues (Fig. 5A). Tracer uptake in the ROI of ischemic myocardium (white arrow) reached a peak $(0.35 \pm 0.053 \% \mathrm{ID} / \mathrm{g})$ at $8 \mathrm{~h}$ post-MI/R, which was not observed in the sham-operated 
A

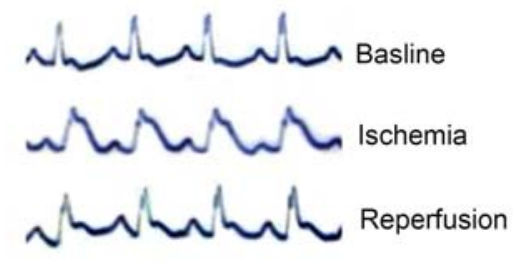

B

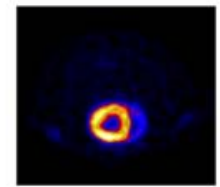

Sham

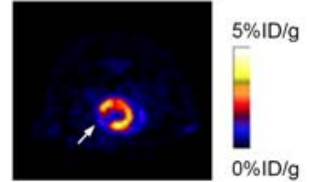

Day 1
C

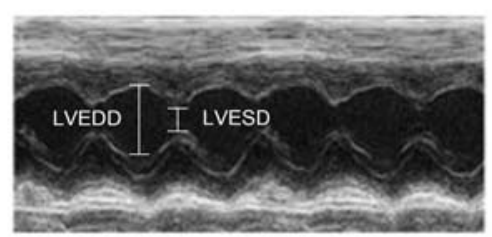

Sham

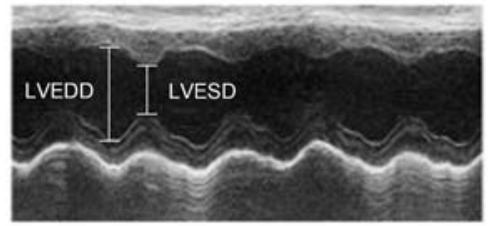

Day 1

Figure 3. Characterization of MI/R model. (A) Echocardiogram changes during ischemia and reperfusion. (B) Positron emission tomography of sham-operated rats and rats submitted to MI/R at 1 day after operation using ${ }^{18} \mathrm{~F}$-fluorodeoxyglucose. White arrow indicates the anterolateral wall of the LV. (C) M-mode ultrasound at mid-ventricle level at 1 day after MI/R compared to that of sham operated group. ${ }^{18} \mathrm{~F}$, fluorine-18; \% ID/g, percentage of injected dose per gram; $\mathrm{MI} / \mathrm{R}$, myocardial ischemia and reperfusion; $\mathrm{LV}$, left ventricle.
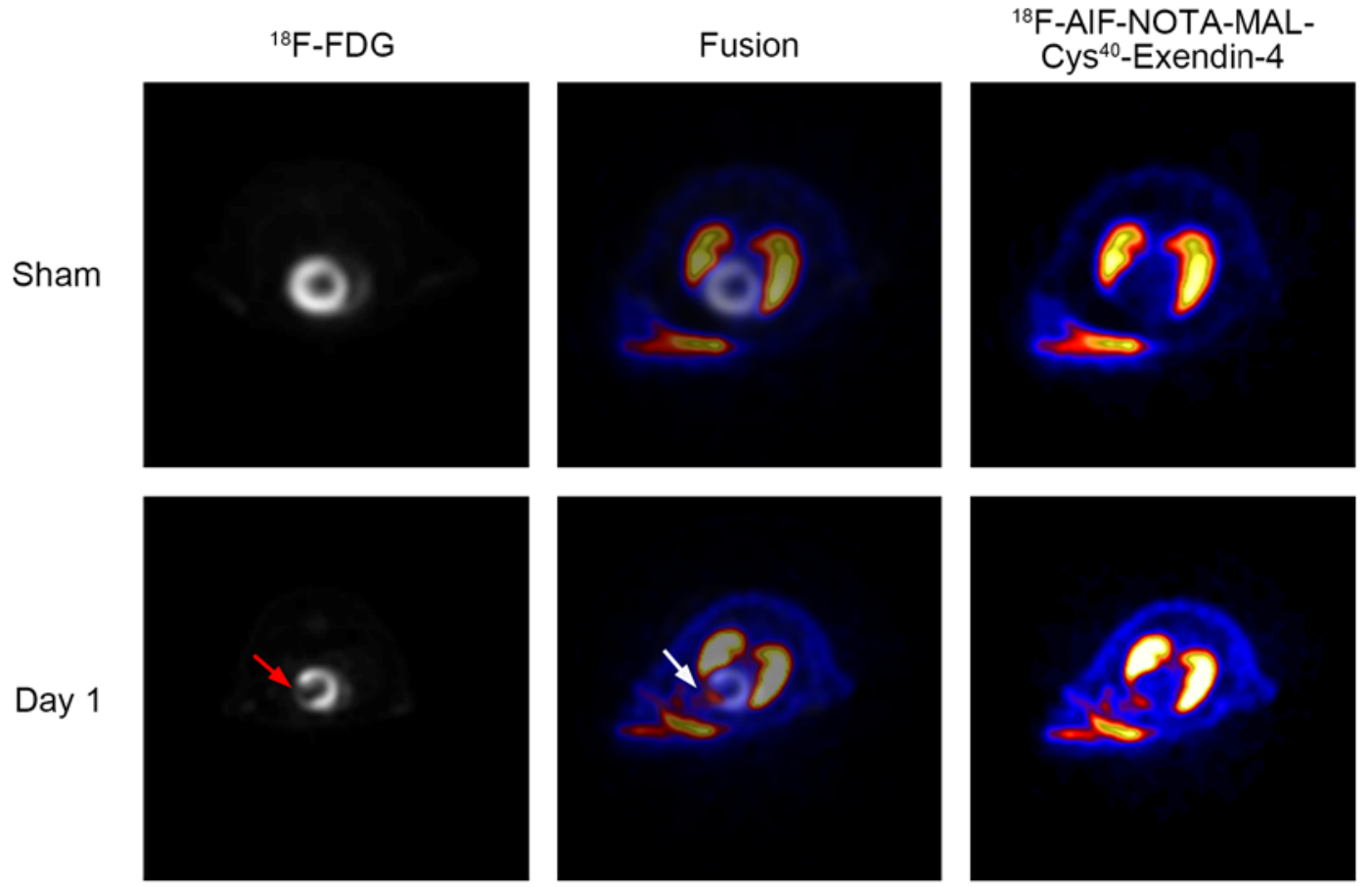

Figure 4. Co-registration of ${ }^{18} \mathrm{~F}$-AlF-NOTA-MAL-Cys ${ }^{40}$-exendin-4 PET with ${ }^{18} \mathrm{~F}-\mathrm{FDG}$ positron emission tomography. Coronary artery ligation decreased ${ }^{18} \mathrm{~F}$-FDG accumulation (red arrow) and increased ${ }^{18} \mathrm{~F}$-AlF-NOTA-MAL-Cys ${ }^{40}$-exendin-4 accumulation (white arrow). ${ }^{18} \mathrm{~F}$, fluorine-18; AlF, aluminum fluoride; Cys, cysteine; FDG, fluorodeoxyglucose; MAL, maleimide; NOTA, 1,4,7-triazacyclononanetriacetic acid.

group $(0.06 \pm 0.012 \% \mathrm{ID} / \mathrm{g} ; \mathrm{n}=6$; Fig. $5 \mathrm{~B})$. In addition, the radioactivity level remained high at post-MI/R day $1(0.20 \pm 0.032$ $\% \mathrm{ID} / \mathrm{g} ; \mathrm{n}=6)$ and decreased on day $3(0.16 \pm 0.017 \% \mathrm{ID} / \mathrm{g} ; \mathrm{n}=4$; Fig. 5B). Minimal tracer uptake persisted at 1 week post-MI/R $(0.08 \pm 0.006 \% \mathrm{ID} / \mathrm{g} ; \mathrm{n}=6)$, but the levels were not significantly different (Fig. 5B).

To further test the GLP-1R binding specificity of ${ }^{18} \mathrm{~F}-\mathrm{AlF}-$ NOTA-MAL-Cys ${ }^{40}$-exendin- 4 , unlabeled exendin- 4 was used as a blocking agent. Tracer uptake was significantly lower compared with unblocked rats at post-MI/R day $1(0.09 \pm 0.041$ vs. $0.20 \pm 0.02 \% \mathrm{ID} / \mathrm{g}$, respectively; $\mathrm{P}<0.05$; Fig. $5 \mathrm{~A}$ and B).

Ischemic operation did not affect lung uptake of the radiotracer. The \%ID/g of the lung remained high throughout the experiment (from $8 \mathrm{~h}$ to 1 week following MI/R) at $1.19 \pm 0.25$ (n=6; Fig. 5C). ${ }^{18} \mathrm{~F}-\mathrm{AlF}-\mathrm{NOTA}-\mathrm{MAL}-\mathrm{Cys}^{40}$-exendin-4 accumulation within the surgical wound (yellow arrows) was $0.42 \pm 0.12 \% \mathrm{ID} / \mathrm{g}$ at $8 \mathrm{~h}$ following MI/R (Fig. $5 \mathrm{C}$ ).

Western blotting and immunohistochemical staining. To verify the direct relation between GLP-1R upregulation and high uptake of ${ }^{18} \mathrm{~F}$-ALF-NOTA-MAL-Cys ${ }^{40}$-exendin-4, western blot analysis and immunohistochemical staining were preformed using a GLP-1R-specific antibody on myocardial samples from MI/R and sham-operated rats. GLP-1R protein level increased at $8 \mathrm{~h}$ post-MI/R compared with the sham-operated group $(\mathrm{P}<0.05$; Fig. $6 \mathrm{~A})$, and the dynamic change observed later was consistent with that of tracer uptake (Fig. 5B). The immunostaining results revealed notably 
A

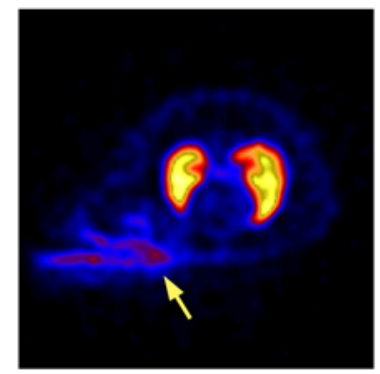

Sham

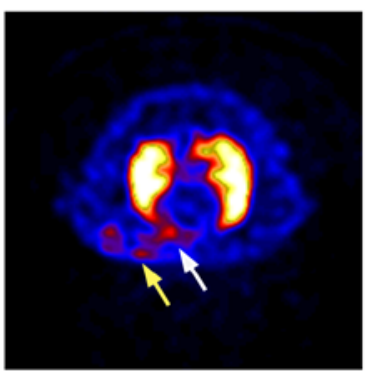

3 days

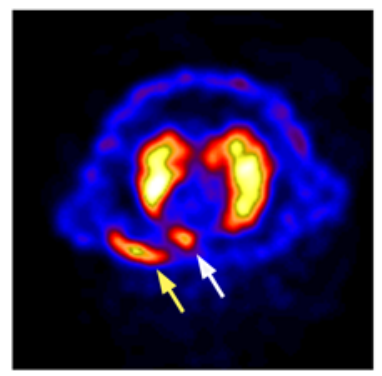

8 hours

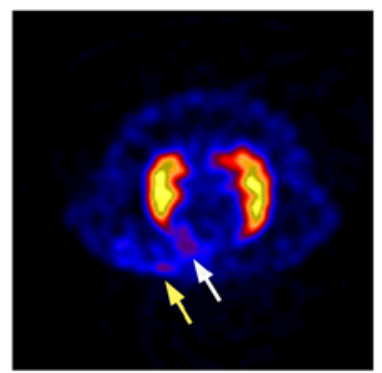

1 week

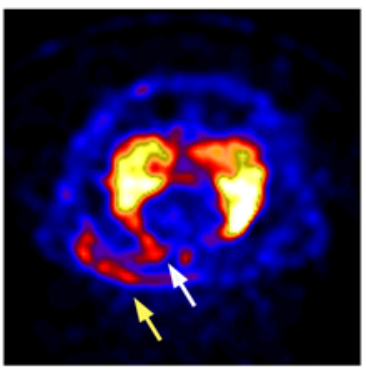

1 day

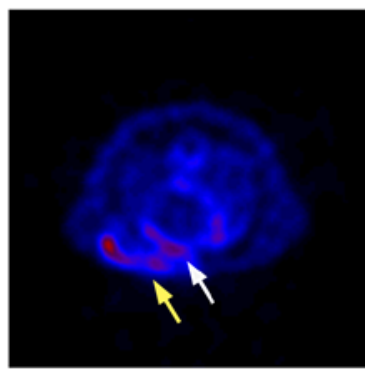

1 day blocking
$5 \% \mathrm{ID} / \mathrm{g}$

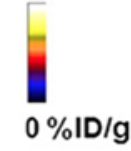

$0 \% \mathrm{ID} / \mathrm{g}$
B

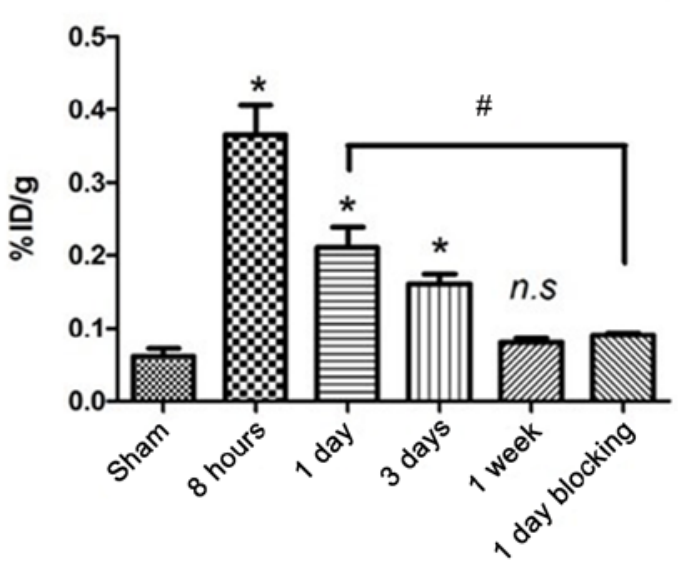

C

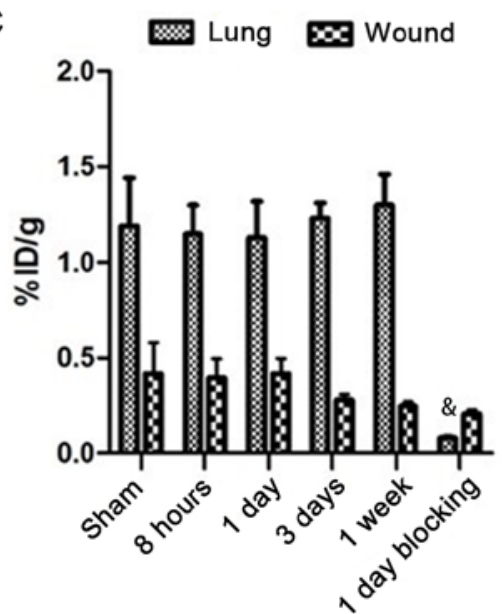

Figure 5. Longitudinal PET imaging of ${ }^{18} \mathrm{~F}$-AlF-NOTA-MAL-Cys ${ }^{40}$-exendin-4 in rats following MI/R. (A) Representative transaxial positron emission tomography images using ${ }^{18} \mathrm{~F}$-AlF-NOTA-MAL-Cys ${ }^{40}$-exendin- 4 at different time points following MI/R. High ${ }^{18}$ F-AlF-NOTA-MAL-Cys ${ }^{40}$-exendin- 4 accumulation region in infarcted/ischemic myocardium is indicated by white arrows. High tracer uptake was detected in the lungs and did not change over time. In surgical wounds (yellow arrows), tracer uptake decreased over time. (B) Quantification of ${ }^{18} \mathrm{~F}-\mathrm{AlF}-\mathrm{NOTA}-\mathrm{MAL}-\mathrm{Cys}{ }^{40}$-exendin-4 accumulation in infarcted/ischemic myocardium following MI/R over time, expressed as \%ID/g of tissue. (C) Quantification of ${ }^{18} \mathrm{~F}-\mathrm{AlF}-\mathrm{NOTA}-\mathrm{MAL}-\mathrm{Cys}{ }^{40}$-exendin-4 accumulation in lung and surgical wound region following $\mathrm{MI} / \mathrm{R}$ over time, expressed as $\% \mathrm{ID} / \mathrm{g}$ of tissue. ${ }^{*} \mathrm{P}<0.05$ vs. sham; ${ }^{\prime \prime} \mathrm{P}<0.05$ vs. $8 \mathrm{~h} ;{ }^{~} \mathrm{P}<0.05$ vs. 1 day. ${ }^{18} \mathrm{~F}$, fluorine-18; $\% \mathrm{ID} / \mathrm{g}$, percentage of injected dose per gram; AlF, aluminum fluoride; Cys, cysteine; MAL, maleimide; MI/R, myocardial ischemia and reperfusion; NOTA, 1,4,7-triazacyclononanetriacetic acid.

enhanced cardiomyocyte staining of GLP-1R at $8 \mathrm{~h}$ and 1 day post-MI/R compared with the sham-operated group. The staining density decreased with time and returned to control levels in 1 week (Fig. 6B).

\section{Discussion}

Reperfusion injury is a complex process that involves a series of signaling pathways (21). From extracellular ligands to intracellular signal cascades, receptors serve a key role in delivering signals. GLP-1 and its analogs have been reported to exert cardioprotective effects in several experimental models and preliminary clinical trials, but the underlying mechanism has yet to be studied $(22,23)$. Therefore, an effective method for monitoring in vivo dynamic changes in GLP-1R expression may be of great value.

PET imaging is a promising method for receptor imaging for research use; however, the synthesis of radiotracers for PET requires consideration of biological and chemical issues. Several positron-emitting radionuclides have been used for PET imaging in the laboratory $\left({ }^{64} \mathrm{Cu},{ }^{68} \mathrm{Ga},{ }^{18} \mathrm{~F},{ }^{11} \mathrm{C}\right)$, among which ${ }^{18} \mathrm{~F}$ stands out for its ideal imaging properties and may have the potential to be translated into clinical practice $(14,24)$. The $\mathrm{T}_{1 / 2}$ of ${ }^{18} \mathrm{~F}$ (109.8 min) allows long-duration, multistep radiosynthesis, and the relatively low positron emission energy $(0.64 \mathrm{MeV})$ provides a short tissue range, thus allowing generation of high-resolution images (25). However, combining ${ }^{18} \mathrm{~F}$ with target peptides has remained a challenge. In our 

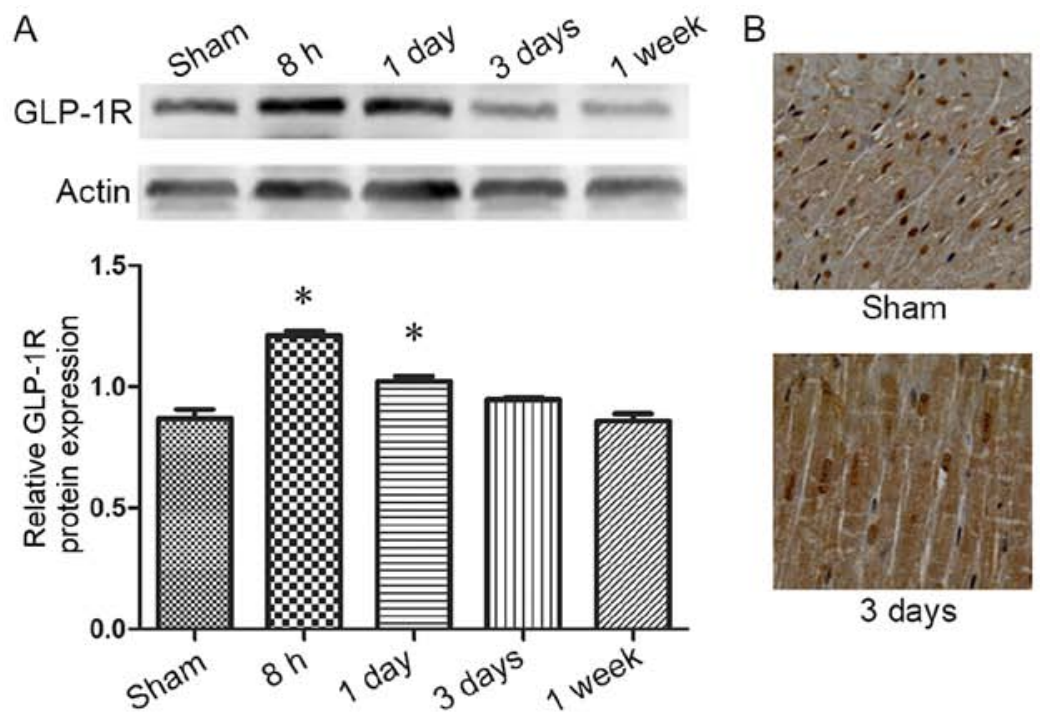

Sham

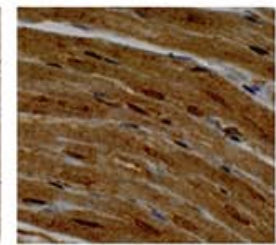

$8 \mathrm{~h}$

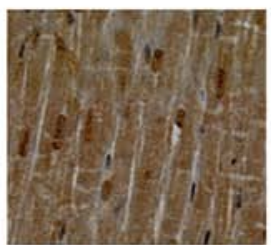

3 days

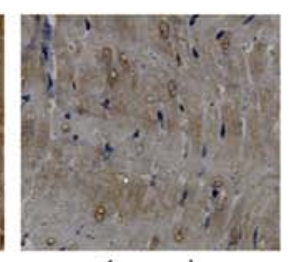

1 week

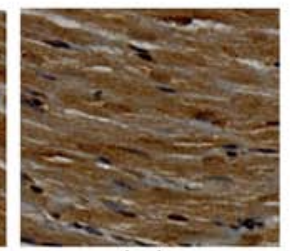

1 day

Figure 6. Analyses of GLP-1R expression via western blotting and immunohistochemical staining. (A) Western blotting and semi-quantitative densitometric analyses of GLP-1R in the anterolateral wall of the heart at different time points following MI/R. (B) Immunohistochemical staining of sham-operated and infarcted/ischemic myocardial tissues at different time points following MI/R. Magnification, x 200 . ${ }^{*}<0.05$ vs. sham group. GLP-1R, glucagon-like peptide-1 receptor; $\mathrm{MI} / \mathrm{R}$, myocardial ischemia and reperfusion.

previous study, ${ }^{18} \mathrm{~F}-\mathrm{FBEM}-\mathrm{Cys}{ }^{40}$-exendin-4 was developed, which exhibited high and receptor-specific accumulation in INS-1 rat insulinoma models (17). However, the synthesis of ${ }^{18} \mathrm{~F}-\mathrm{FBEM}-\mathrm{Cys}{ }^{40}$-exendin- 4 requires a multistep procedure, specialized equipment and well-trained personnel, which may counteract the advantages that enable the tracer to translate into clinical practice.

In the present study, a novel GLP-1R specific radiotracer was synthesized by conjugating ${ }^{18} \mathrm{~F}$-AlF to NOTA-MAL-Cys ${ }^{40}$-exendin-4; the entire process required only one step and was completed in $30 \mathrm{~min}$, which was notably less compared with the time required to synthesize ${ }^{18} \mathrm{~F}$-FBEM-Cys ${ }^{40}$-exendin-4 (17) and other GLP-1R-based radiotracers such as ${ }^{18} \mathrm{~F}-\mathrm{FBEM}-\mathrm{EM} 3106 \mathrm{~B}$ (26) and ${ }^{18} \mathrm{~F}-\mathrm{FBEM}-\mathrm{Cys}{ }^{39}$-exendin-4 (27). The yield of ${ }^{18} \mathrm{~F}$-AlF-NOTAMAL-Cys ${ }^{40}$-exendin-4 was moderate at $18.5 \pm 3.4 \%$ (not decay corrected), with a purity of $>95 \%$. No HPLC purification was required, thus simplifying the synthesis process.

Longitudinal PET in a rat model of MI/R with ${ }^{18} \mathrm{~F}-\mathrm{AlF}$ NOTA-MAL-Cys ${ }^{40}$-exendin- 4 was performed. Ischemic myocardium, lung and surgical wounds showed higher tracer accumulation compared with other tissues. Pre-injected unlabeled $\mathrm{Cys}^{40}$-exendin-4 significantly blocked tracer accumulation, which indicated that the accumulation of ${ }^{18}$ F-AlF-NOTA-MAL-Cys ${ }^{40}$-exendin-4 was GLP-1R-specific. Preliminary western blotting experiments demonstrated that GLP-1R expression was highest at $8 \mathrm{~h}$ following ischemia/reperfusion injury; therefore, $8 \mathrm{~h}$ was indicated as a critical time point. Compared with focal tracer uptake in ischemic myocardium at $8 \mathrm{~h}, 1$ day, 3 days, and 1 week following the onset of ischemia, tracer uptake reached the highest level at $8 \mathrm{~h}$ post-MI/R; tracer accumulation then decreased over time. At 1 week post-MI/R, tracer uptake within ischemic myocardium was restored to the near-normal level. The performance of ${ }^{18} \mathrm{~F}$-AlF-NOTA-MAL-Cys ${ }^{40}$-exe ndin- 4 as a radiotracer in rat hearts was similar to that of
${ }^{18}$ F-FBEM-Cys ${ }^{40}$-exendin-4 (18). The results of western blotting and immunohistochemical staining were consistent with PET. Thus, a non-invasive method for molecular imaging was established to monitor dynamic changes in GLP-1R expression in ischemic myocardium in vivo. However, the experiments conducted in the present study offered only indirect evidence of association of the analog with GLP-1R, and the mechanism by which reperfusion induces GLP-1R upregulation remains unclear and requires further investigation.

Lung tissue exhibited higher tracer accumulation compared with ischemic myocardium at all time points owing to high levels of GLP-1R expression, which may compromise the value of ${ }^{18} \mathrm{~F}$-AlF-NOTA-MAL-Cys ${ }^{40}$-exendin- 4 in clinical use. However, considering that human lung tissue expresses significantly lower levels of GLP-1R compared with rat lung tissue, the ischemic myocardium-to-lung ratio of tracer uptake may be higher in humans (28). The analog may be eliminated through the lungs in a pharmacokinetic pathway, which requires further investigation. Surgical wounds exhibited increased tracer accumulation that could not be completely blocked with unlabeled $\mathrm{Cys}^{40}$-exendin-4. Thus, the increased accumulation of tracer in surgical wounds may have been due to increased vascular permeability caused by inflammatory reaction.

The results of the present preliminary evaluation of ${ }^{18}$ F-AlF-NOTA-MAL-Cys ${ }^{40}$-exendin-4 revealed a dynamic pattern of GLP-1R expression following MI/R in rats, which suggested that GLP-1 may exert its cardioprotective effects early following $\mathrm{MI} / \mathrm{R}$, when GLP-1R expression is relatively high. After 1 week, the therapeutic effect of GLP-1 may be compromised owing to low receptor expression. Consistent with the present study, previous studies demonstrated that the administration of GLP-1R agonists during the early stages of acute cardiac ischemia protected against MI/R injury $(9,29)$.

In conclusion, ${ }^{18} \mathrm{~F}$-AlF-NOTA-MAL-Cys ${ }^{40}$-exendin-4 was synthesized in a time-efficient and effective way. PET imaging 
using ${ }^{18} \mathrm{~F}$-AlF-NOTA-MAL-Cys ${ }^{40}$-exendin-4 displayed high ischemic myocardium-to-background radioactivity ratios, and further analysis revealed dynamic changes in GLP-1R expression in rats following $\mathrm{MI} / \mathrm{R}$. The radiotracer offers a new approach to observe the dynamic changes of GLP-1R expression following $\mathrm{MI} / \mathrm{R}$ injury, which may help clinicians make decisions regarding the exact time points of GLP-1R agonist administration during MI/R injury treatment.

\section{Acknowledgements}

Not applicable.

\section{Funding}

The present study was supported by The National Natural Science Foundation of China (grant no. 81570210).

\section{Availability of data and materials}

The datasets used and/or analyzed during the current study are available from the corresponding author on reasonable request.

\section{Authors' contributions}

XP established the myocardial ischemia/reperfusion rat models, performed positron emission tomography imaging and wrote the manuscript. QX synthesized the radiotracer and contributed to the acquisition of data. JC established the animal models. TW performed western blot analysis and immunohistochemical staining. MZ analyzed the data and revised the manuscript. HW and HG designed the experiments and critically revised the manuscript.

\section{Ethics approval and consent to participate}

All animal studies were conducted in accordance with the principles and procedures outlined in the Guide for the Care and Use of Laboratory Animals, and the protocols were approved by the Laboratory Animal Ethics Committee of The Fourth Military Medical University (Xi'an, China).

\section{Patient consent for publication}

Not applicable.

\section{Competing interests}

The authors declare that they have no competing interests.

\section{References}

1. Benjamin EJ, Blaha MJ, Chiuve SE, Cushman M, Das SR Deo R, de Ferranti SD, Floyd J, Fornage M, Gillespie C, et al: Heart disease and stroke statistics-2017 update: A report from the American Heart Association. Circulation 135: e146-e603, 2017.

2. Jennings RB, Sommers HM, Smyth GA, Flack HA and Linn H: Myocardial necrosis induced by temporary occlusion of a coronary artery in the dog. Arch Pathol 70: 68-78, 1960.

3. Jordan JE, Zhao ZQ and Vinten-Johansen J: The role of neutrophils in myocardial ischemia-reperfusion injury. Cardiovasc Res 43: 860-878, 1999.
4. Lesnefsky EJ, Chen Q, Tandler B and Hoppel CL: Mitochondrial dysfunction and myocardial ischemia-reperfusion: Implications for novel therapies. Annu Rev Pharmacol Toxicol 57: 535-565, 2017.

5. Ferdinandy P, Hausenloy DJ, Heusch G, Baxter GF and Schulz R: Interaction of risk factors, comorbidities, and comedications with ischemia/reperfusion injury and cardioprotection by preconditioning, postconditioning, and remote conditioning. Pharmacol Rev 66: 1142-1174, 2014.

6. Drucker DJ: The biology of incretin hormones. Cell Metab 3: 153-165, 2006.

7. Theodorakis MJ, Carlson O, Michopoulos S, Doyle ME, Juhaszova M, Petraki K and Egan JM: Human duodenal enteroendocrine cells: Source of both incretin peptides, GLP-1 and GIP. Am J Physiol Endocrinol Metab 290: E550-E559, 2006.

8. Holst JJ, Deacon CF, Vilsboll T, Krarup T and Madsbad S: Glucagon-like peptide-1, glucose homeostasis and diabetes. Trends Mol Med 14: 161-168, 2008.

9. Sonne DP, Engstrom T and Treiman M: Protective effects of GLP-1 analogues exendin-4 and GLP-1(9-36) amide against ischemia-reperfusion injury in rat heart. Regul Pept 146: 243-249, 2008.

10. Noyan-Ashraf MH, Momen MA, Ban K, Sadi AM, Zhou YQ, Riazi AM, Baggio LL, Henkelman RM, Husain $M$ and Drucker DJ: GLP-1R agonist liraglutide activates cytoprotective pathways and improves outcomes after experimental myocardial infarction in mice. Diabetes 58: 975-983, 2009.

11. Bose AK, Mocanu MM, Carr RD, Brand CL and Yellon DM: Glucagon-like peptide 1 can directly protect the heart against ischemia/reperfusion injury. Diabetes 54: 146-151, 2005.

12. Deacon CF, Johnsen AH and Holst JJ: Degradation of glucagon-like peptide-1 by human plasma in vitro yields an $\mathrm{N}$-terminally truncated peptide that is a major endogenous metabolite in vivo. J Clin Endocrinol Metab 80: 952-957, 1995.

13. Eng J, Kleinman WA, Singh L, Singh G and Raufman JP: Isolation and characterization of exendin-4, an exendin-3 analogue, from Heloderma suspectum venom. Further evidence for an exendin receptor on dispersed acini from guinea pig pancreas. J Biol Chem 267: 7402-7405, 1992.

14. Mikkola K, Yim CB, Fagerholm V, Ishizu T, Elomaa VV, Rajander J, Jurttila J, Saanijoki T, Tolvanen T, Tirri M, et al: $64 \mathrm{Cu}-$ and $68 \mathrm{Ga}-\mathrm{labelled}$ [Nle(14),Lys(40)(Ahx-NODAGA) $\mathrm{NH} 2$ ]-exendin-4 for pancreatic beta cell imaging in rats. Mol Imaging Biol 16: 255-263, 2014.

15. Wild D, Behe M, Wicki A, Storch D, Waser B, Gotthardt M, Keil B, Christofori G, Reubi JC and Mäcke HR: [Lys40(Ahx-DTPA-111In)NH2] exendin-4, a very promising ligand for glucagon-like peptide-1 (GLP-1) receptor targeting. J Nucl Med 47: 2025-2033, 2006.

16. Sowa-Staszczak A, Pach D, Mikolajczak R, Mäcke H, Jabrocka-Hybel A, Stefańska A, Tomaszuk M, Janota B, Gilis-Januszewska A, Małecki M, et al: Glucagon-like peptide-1 receptor imaging with [Lys40(Ahx-HYNIC-99mTc/EDDA) NH2]-exendin-4 for the detection of insulinoma. Eur J Nucl Med Mol Imaging 40: 524-531, 2013.

17. Kiesewetter DO, Gao H, Ma Y, Niu G, Quan Q, Guo N and Chen X: 18F-radiolabeled analogs of exendin-4 for PET imaging of GLP-1 in insulinoma. Eur J Nucl Med Mol Imaging 39: 463-473, 2012.

18. Gao H, Kiesewetter DO, Zhang X, Huang X, Guo N, Lang L, Hida N, Wang H, Wang H, Cao F, et al: PET of glucagonlike peptide receptor upregulation after myocardial ischemia or reperfusion injury. J Nucl Med 53: 1960-1968, 2012.

19. Kiesewetter DO, Guo N, Guo J, Gao H, Zhu L, Ma Y, Niu G and Chen X: Evaluation of an [(18)F]AlF-NOTA analog of exendin-4 for imaging of GLP-1 receptor in insulinoma. Theranostics 2: 999-1009, 2012.

20. Silverman J, Mark A and Murthy S: The Iacuc Handbook. Iacuc Handbook, 2000.

21. Eltzschig HK and Eckle T: Ischemia and reperfusion-from mechanism to translation. Nat Med 17: 1391-1401, 2011.

22. Timmers L, Henriques JP, de Kleijn DP, Devries JH, Kemperman H, Steendijk P, Verlaan CW, Kerver M, Piek JJ, Doevendans PA, et al: Exenatide reduces infarct size and improves cardiac function in a porcine model of ischemia and reperfusion injury. J Am Coll Cardiol 53: 501-510, 2009

23. Dawwas GK, Smith SM and Park H: Risk of heart failure hospitalization among users of dipeptidyl peptidase- 4 inhibitors compared to glucagon-like peptide-1 receptor agonists. Cardiovasc Diabetol 17: 102, 2018. 
24. Miller PW, Long NJ, Vilar R and Gee AD: Synthesis of 11C, $18 \mathrm{~F}, 15 \mathrm{O}$, and $13 \mathrm{~N}$ radiolabels for positron emission tomography. Angew Chem Int Ed Engl 47: 8998-9033, 2008.

25. McBride WJ, D'Souza CA, Sharkey RM, Karacay H, Rossi EA Chang $\mathrm{CH}$ and Goldenberg DM: Improved $18 \mathrm{~F}$ labeling of peptides with a fluoride-aluminum-chelate complex. Bioconjug Chem 21: 1331-1340, 2010

26. Gao H, Niu G, Yang M, Quan Q, Ma Y, Murage EN, Ahn JM, Kiesewetter DO and Chen X: PET of insulinoma using (1)(8) F-FBEM-EM3106B, a new GLP-1 analogue. Mol Pharm 8: 1775-1782, 2011.

27. Xu Y, Pan D, Xu Q, Zhu C, Wang L, Chen F, Yang R, Luo S and Yang $\mathrm{M}$ : Insulinoma imaging with glucagon-like peptide-1 receptor targeting probe (18)F-FBEM-Cys (39)-exendin-4. J Cancer Res Clin Oncol 140: 1479-1488, 2014.
28. Korner M, Stockli M, Waser B and Reubi JC: GLP-1 receptor expression in human tumors and human normal tissues: Potential for in vivo targeting. J Nucl Med 48: 736-743, 2007.

29. Nikolaidis LA, Mankad S, Sokos GG, Miske G, Shah A, Elahi D and Shannon RP: Effects of glucagon-like peptide-1 in patients with acute myocardial infarction and left ventricular dysfunction after successful reperfusion. Circulation 109: 962-965, 2004.

(i) (9) This work is licensed under a Creative Commons Attribution-NonCommercial-NoDerivatives 4.0 International (CC BY-NC-ND 4.0) License. 